\title{
From Waste to Wealth: Identifying the Economic Impact of the Recycling Sector in Malaysia
}

\author{
Chakrin Utit ${ }^{a}$ \\ Anitha Rosland ${ }^{b}$ \\ M. Yusof Saari ${ }^{c}$ \\ Muhammad Daaniyall Abd Rahman ${ }^{\mathrm{d}}$ \\ Universiti Putra Malaysia
}

\begin{abstract}
This paper assesses the economic impact of the recycling sector in Malaysia to gauge its potential for strengthening green-based economic growth in alignment with the Sustainable Development Goals (SDGs). This study employs a comparative impact assessment to analyse the input-output multiplier and linkages using the national input-output tables for 2005, 2010 and 2015. Our results indicate that the recycling sector has high potential to transform waste to wealth from which its value-added multiplier is sufficiently high and is also reinforced with high spillover effects. The recycling sector is identified as a strategic sector, where approximately $70 \%$ of its products are embodied in intermediate demand. This sector conforms to circular economy practices as other sectors in the economy are utilising recyclables for remanufacturing purposes. The value-added footprint level of the recycling sector also shows an increasing trend that implies its growing importance in supporting the growth of other production sectors in the economy. At the sectoral level, most of the recyclables are utilised by the Wholesale and Retail Trade sector. Hence, our work emphasises the importance of prioritising the recycling sector in development plans, as well as improving and strengthening the backward linkages between the recycling sector with other production sectors.
\end{abstract}

Keywords: Economic impact, embodied recycled materials, input-output analysis, recycling sector

JEL classification: Q50, Q53, D57

\section{Introduction}

In the past few decades, rapid economic growth and urbanisation have contributed to the improvement of living standards for large fractions of the world population (Singh et al., 2014). However, the growth comes with a cost to the environment, whereby

a School of Business and Economics, Universiti Putra Malaysia, 43400 UPM, Serdang, Selangor, Malaysia. Email: gs49595@student.upm.edu.my or uchakrin@gmail.com

b School of Business and Economics, Universiti Putra Malaysia, 43400 UPM, Serdang, Selangor, Malaysia. Email: anitharosland@upm.edu.my (Corresponding Author)

c School of Business and Economics, Universiti Putra Malaysia, 43400 UPM, Serdang, Selangor, Malaysia. Email: yusofsaari_upm@upm.edu.my

d School of Business and Economics, Universiti Putra Malaysia, 43400 UPM, Serdang, Selangor, Malaysia. Email: daaniyall@upm.edu.my

Article Info: Received 12 May 2020; Revised 20 January 2021; Accepted 29 March 2021 https://doi.org/10.22452/MJES.vol58no1.7 
the increasing resource consumption leads to the growing amount of waste (GerbensLeenes et al., 2010; Wu \& Niu, 2008). It is projected that global waste is expected to grow from 2.01 billion tonnes in 2016 to 3.4 billion tonnes by 2050 (World Bank, 2018).

Besides the economic and urbanisation factors, the growing amount of waste also links to trade activities through the trading of waste products such as steel scrap and plastic. Trade statistics show that about 97.1 million tonnes of steel scrap are traded in 2014, and about 299 million tonnes of plastic waste are traded in 2013 (United Nations Environment Programme, 2015). Globally, the topic of waste trade has been widely discussed since the 1980s, covering legal, political, environmental, economic and social perspectives (see Baggs, 2009; Lipman, 2002; Strohm, 1993; Wynne, 1989).

Over the years, waste trade has become a serious policy concern when exporters of waste targeted developing countries as their export destinations (Lipman, 2002). Empirical evidence showed that about $45 \%$ of the world plastic waste flows into China before the plastic waste import restriction imposed by the Chinese government in 2018 (Wang et al., 2019). In 2019, several reports and studies showed that Malaysia had replaced China as the leading export destination after the import ban (Wang et al., 2019).

The sudden shift in the waste trade destinations coupled with the unexpected high exports of plastic waste to Malaysia presents a significant challenge from the waste management perspective. As an immediate response, the Malaysian government retaliated by shipping the plastic waste back to the exporting countries and subsequently banned its import. Although the retaliation measure is a quick-fix option, this might not be sustainable because such action can otherwise promote illegal trading activities. In line with this argument, evidence shows that waste is exported in disguise as recyclables or second-hand goods (Elliott, 2007; Hotta et al., 2008; Ray, 2008).

The issue in question is whether the waste exports are for recycling activities or waste disposal purposes. While statistics showed that overall recycling rate in Malaysia is relatively low at $28.1 \%$ in 2019 (Department of Statistics Malaysia [DOSM], 2020), past study revealed that the management of solid waste system, which include plastic waste, in the developing countries, including Malaysia, displayed an array of issues such as crude open dumping and burning (Manaf et al., 2009). This clearly exposes questionable waste management practices that prompt the need to measure the importance of market and non-market values of the waste industry by using economic instruments. Such information, in the form of cost and benefit analysis, is vital as a guide for public policy, governance and regulation.

From the economic point of view, it is feasible to promote the recycling sector as a new source of growth, especially in the realm of growing circular economic stance. It emphasises on transforming waste into wealth through active remanufacturing that involves processing waste into higher quality materials to be used by other industries. This highlights the role of the recycling sector in the supply chain and the 'footprint of recycles' in the production ecosystem. Thus, in addition to reducing waste, strengthening the recycling sector could be explored to promote economic growth.

To reveal the importance and understand the potential of the recycling sector, this paper aims to assess its economic impacts using input-output modelling technique. The model allows us to quantify the multiplier impact and intensity of intersectoral linkages 
(i.e. backward and forward linkages) of the recycling sector to determine its economic importance in the supply chain. Furthermore, the model also allows for the assessment of the sector's footprints in the economy.

It is important to note that our work offers significant contributions to scientific knowledge and policy analysis by analysing the economic impacts of the recycling sector. In relation to scientific knowledge, this paper explores the use of the hypothetical extraction method (HEM) for impact assessment. Although there are studies that have applied a similar method for impacts analysis in Malaysia, the number of literature are rather scarce. For policy analysis, this paper helps policymakers to understand the economic impact of the recycling sector. In the absence of a thorough study, the economic impact of the recycling sector may not be properly observed, which in turn affects the economic planning process.

This paper is structured into five sections. Section 2 discusses the literature gaps that justify our contribution to the literature. Section 3 explains the methodological approach for the assessment of the economic impact of the recycling sector in Malaysia. Section 4 presents the main findings from the analyses. Finally, section 5 concludes with policy implications.

\section{Contribution to the Literature}

Our literature survey indicates that this paper fulfils two major research gaps. First, the number of studies that addressed the economic importance of the recycling sector is small. Second, most of the studies, particularly in Malaysia, applied partial equilibrium methods that omit the economic-wide impact at the sectoral level. A general equilibrium method, such as the input-output analysis, can render this impact. Thus, our paper provides an empirical contribution to the literature by addressing the listed research gaps.

In Malaysia, vast amount of literature are found to focus on the recycling sector. However, the number of studies that primarily focus on assessing its economic impacts are limited. Most of the studies were mainly interested in investigating issues such as policy evolution and challenges, waste management and recycling activities, and factors that contribute to recycling behaviour (see Hassan et al., 2000; Hong \& Narayanan, 2006; Moh \& Manaf, 2014, 2017; Periathamby et al., 2009; Ramayah et al., 2012).

In relation to policy evolution and challenges, previous studies focused on the national waste management bill and the challenges in managing waste in Malaysia. In 2007, the Solid Waste and Public Cleansing Management (SWPCM) Bill 2007 was passed by the Malaysian parliament after debating for ten years (Johari et al., 2014; Periathamby et al., 2009). Before the full implementation of the bill in September 2011, solid waste management and public cleansing activities were managed by the local authorities.

Despite the bill implementation, there are several challenges, such as the increase in solid waste amount and management cost that lead to reduced waste management efficiency (Moh \& Manaf, 2014; Periathamby et al., 2009). The process of incorporating recycling into the existing solid waste management was also challenging because 
different sets of goals are needed for different time periods (Hassan et al., 2000). For example, short-term goals must focus on planning and implementation activities. Meanwhile, long-term goals need to focus on expanding the recycling program and attaining the mandated waste reduction-recycling goals.

From the perspective of waste management and recycling activities, many studies in Malaysia focused on issues such as source separation and recycling practices. For instance, Moh and Manaf (2017) emphasised that the sense of responsibility and awareness on the implications of not separating waste for recycling are critically lacking among Malaysians. For the low-income group with a low level of education, monetary incentives become the main hindrance for not engaging in the recycling activity (Zen et al., 2014). Most of the efforts to separate and recycle in Malaysia are only initiated by the informal sectors, such as non-governmental organisations (NGOs), private contractors and scavengers (JICA, 2006; Moh \& Manaf, 2017).

In addition, understanding the recycling behaviour is most important when addressing the issues of waste management and recycling activities in Malaysia. Hong and Narayanan (2006) and Ramayah et al. (2012) argued that environmental awareness plays a major role in promoting better waste management and recycling in the society. To encourage recycling behaviour, Hong and Narayanan (2006) and Mohamad et al. (2012) accentuated the importance of public campaigns and education. Religious communities are positively contributing to the recycling practice among their devotees in Malaysia (Mohamad et al., 2012). As these studies were mainly conducted using the micro-level or bottom-up approach to understanding the importance of the recycling sector, there is also a need to configure a top-down approach for the policymakers, with empirical evidence through an appropriate methodology.

Empirical evidence on the recycling sector in Malaysia is limited, but past literature review shows that most studies applied partial equilibrium methods, particularly econometric models. For example, Hong and Narayanan (2006) and Begum et al. (2009) employed the logit regression model. Other widely utilised methodologies are the survey-based technique and the environmental valuation technique, which focused more on micro-level assessment. Studies that utilised the survey-based technique include Mohamad et al. (2012), Murad and Siwar (2007), Omran et al. (2009), Ramayah et al. (2012) and Zen and Siwar (2015). Meanwhile, the environmental valuation technique was well-described by Afroz and Masud (2011) and Subhan et al. (2014).

Considering all the research gaps, our work attempts to fulfill them by providing a macro-perspective or economic-wide evidence on the impact of the recycling sector to the Malaysian economy. The relevant methodological approach in fulfilling the research gaps are described in the next section.

\section{Methodological Approach}

To quantify the economic impact of any relevant sectors, the choice of methodological approach will significantly influence the outcome. For this study, the input-output modelling technique is chosen as the main approach for its capability in presenting the snapshot of sectoral interdependencies. Based on this attribute, the model is widely applied for economic analysis (for some basic exposition on input-output analysis, see 
Miller and Blair, 2009). For further discussion on the modelling technique, this section is structured into four subsections. The first subsection presents the structure of the input-output table for Malaysia. The second and third subsections detail the process of developing models for economic impact analyses. Finally, the fourth subsection describes the data source and classification.

\subsection{Structure of the Input-Output Table}

Before exploring into the technical part, it is worth to discuss the structure of an input-output table that serves as the main data set for this study. In general, the table provides a complete picture for the flows of goods and services sold (demand) and bought (supply) in an economy for a given calendar year. Specifically, it illustrates the interdependencies between sectors and their relationship with final consumers.

A simplified structure of an input-output table is shown in Table 1. The columns show the consumption of intermediate inputs, import, tax and value-added (labour and capital) of production sectors in the economy. The rows reflect the amount of output sold by production sectors as intermediate inputs and also to the final demand components. Overall, this table consists of three main components. First, the matrix $\mathbf{Z}$ denotes the intermediate deliveries and each element of $z_{i j}$ indicates the amount of commodity from sector $i$ that is used by sector $j$. Second, vector $f$ represents final demand components - private consumption (c), investment (in), government consumption (g) and export (e). Third, primary input components are represented by the vector $\mathbf{m}$ that gives the sectoral import, vector $\mathbf{t}$ the amount of indirect tax paid to the government, and vector $\mathbf{v}$ the amount of value-added generated. Vector $\mathbf{x}^{\prime}$ is the total input, which equals to total output that is represented by vector $\mathbf{x}$.

Table 1. A simplified structure of input-output table

\begin{tabular}{|c|c|c|c|c|c|c|}
\hline & \multicolumn{3}{|c|}{ Intermediate demand } & \multicolumn{2}{|c|}{ Final demand } & \multirow{2}{*}{$\begin{array}{l}\text { Total } \\
\text { output }\end{array}$} \\
\hline & S1 & S3 & $\mathrm{Sn}$ & C in $\mathbf{g}$ & e & \\
\hline $\begin{array}{l}\text { Sector } 1 \text { (S1) } \\
\text { Sector } 2 \text { (S2) } \\
\text { Sector } 3 \text { (S3) } \\
\text { Sector } n(\mathrm{~S} n)\end{array}$ & \multicolumn{3}{|c|}{$\begin{array}{c}\mathbf{Z} \\
\text { (intermediate demand required among sectors) }\end{array}$} & \multicolumn{2}{|c|}{$\begin{array}{c}\mathbf{f} \\
\text { (final demand) }\end{array}$} & $\begin{array}{c}\mathbf{x} \\
\text { (total } \\
\text { output) }\end{array}$ \\
\hline Import & \multicolumn{3}{|c|}{ m (imported intermediate input) } & & & \\
\hline Tax & \multicolumn{3}{|c|}{ t (indirect tax paid) } & & & \\
\hline Value added & \multicolumn{3}{|c|}{ v (value added) } & & & \\
\hline Total input & \multicolumn{3}{|c|}{$\mathbf{x}^{\prime}$ (total input) } & & & \\
\hline
\end{tabular}

Source: Saari et al. (2018). 
Based on Table 1, a demand-driven model that shows the relationship between output, intermediate inputs and final demand can be described in the following equation:

$$
\begin{aligned}
& \mathbf{x}=\mathbf{Z} \mathbf{i}+(\mathbf{c}+\mathbf{i n}+\mathbf{g}+\mathbf{e}) \\
& \mathbf{x}=\mathbf{Z} \mathbf{i}+\mathbf{f}
\end{aligned}
$$

where $\mathbf{x}$ is the total output, $\mathbf{Z}$ is the intermediate deliveries in which $\mathbf{i}$ represents a column vector of sector $n$, and $\mathbf{f}$ is the final demand vector with its components as defined earlier. Thus, equation (1) implies that the total output is equal to the summation of intermediate inputs and final demand.

The demand-driven model in equation (1) is also known as the Leontief model. The model treats intermediate inputs as endogenous variables, while the final demands are treated as exogenous. Equation (1) can be rewritten into a standard Leontief inputoutput model as follows:

$$
\begin{aligned}
& \mathbf{x}=\mathbf{A x}+(\mathbf{c}+\text { in }+\mathbf{g}+\mathbf{e}) \\
& \mathbf{x}=\mathbf{A x}+\mathbf{f}
\end{aligned}
$$

where $\mathbf{A}$ is the input-output coefficient matrix that shows the input amount that a sector purchases from other sectors per unit of its own output. The input-output coefficient matrix can be expanded by considering an $n$-sector economy with intersectoral transaction matrix (Z) and sectoral total output vector $(\mathbf{x})$ as follows:

$$
\mathbf{A}=\mathbf{Z} \hat{\mathbf{x}}^{-1}
$$

where $\hat{\mathbf{x}}$ is the diagonalised matrix of $\mathbf{x}$ that reflects the intermediate purchase of sector $j$ from sector $i$. Equation (2) then can be solved as follows:

$$
\begin{aligned}
& \mathbf{X}=(\mathbf{I}-\mathbf{A})^{-1} \mathbf{f} \\
& \mathbf{x}=\mathbf{L f}
\end{aligned}
$$

where $\mathbf{I}$ is the identity matrix, and $(\mathbf{I}-\mathbf{A})^{-1} \mathbf{f}$ stands for the Leontief inverse matrix or the multiplier matrix. Specifically, the elements in this matrix show the total output effects for any sector $j$ to satisfy each unit of final demand.

\subsection{Multiplier and Linkages Measures}

In the input-output analysis, analysts present the results from the multiplier and linkages analyses to provide insights for the economic impact of a sector in the economy. The multiplier measures the impact on a specific indicator such as value-added of the total economy, generated from the changes in final demand of a sector (e.g. export growth of recycling sector). In this study, we focus our analysis on value-added multiplier because it is directly related to GDP'.

1 In the system of national accounts (SNA), the production approach of measuring GDP includes the components of value-added and import duty. In 2010 and 2018, value-added represented $99 \%$ of the total Malaysian GDP, while import duty only constituted about $1 \%$. 
To derive value-added multiplier, equation (4) needs to be expanded to capture the impact on value-added. The first step in deriving the multiplier is to derive the sectoral value-added coefficient $r$ as follows:

$$
\mathbf{r}=\mathbf{v x}^{-1}
$$

Each element of the value-added coefficient $\mathbf{r}$ denotes the value-added per unit of output for each sector. By expressing $r$ in a diagonal matrix and introducing it into equation (4), the amount of value-added $\mathbf{v}$ used to produce output for final demand can be derived as:

$$
\mathbf{v}=\hat{\mathbf{r}}(\mathbf{I}-\mathbf{A})^{-1} \mathbf{f}
$$

where $\hat{\boldsymbol{r}}$ is the value-added coefficient that is expressed in the form of a diagonal matrix.

To reveal the full impact of a sector, the use of only value-added multiplier is not sufficient. A sector may have a large value-added multiplier impact, but it does not inform policymakers whether the sector is actively contributing to the growth of other sectors. Commonly, a sector may contribute to the growth of other sectors through the process of buying and selling of intermediate inputs. Thus, additional information on the linkages is required to inform the level of spillover effects, which includes the backward (BL) and forward linkages (FL). Backward linkage measures the level of integration between the recycling sector with sectors that act as its input supplier, while forward linkage measures the level of integration with sectors that act as output buyers from the recycling sector.

$\mathrm{BL}$ and $\mathrm{FL}$ are measured using the normalised index. The recycling sector is considered to have a strong economic integration if the index values for $B L$ and $F L$ are above 1 . Generally, the outcome from the linkages analysis can fall into one of the four potential degrees of linkages:

- If $\mathrm{BL}<1$ and $\mathrm{FL}<1$, the sector is an "independent sector" - it acquires and sells out intermediate inputs less than the average economy.

- If $\mathrm{BL} \geq 1$ and $\mathrm{FL}<1$, the sector is a "driver sector" - it acquires intermediate inputs from other sectors above the average economy, but sells its intermediate inputs less than the average economy.

- If $\mathrm{BL}<1$ and $\mathrm{FL} \geq 1$, the sector is a "strategic sector" - a sector with outputs that are produced to be utilised as intermediate inputs by other sectors in the economy.

- If $\mathrm{BL} \geq 1$ and $\mathrm{FL} \geq 1$, the sector is a "key sector" - it acquires and transfers intermediate inputs above the average economy.

To administer the linkages analysis, a wide range of approaches are available in the literature such as the power of dispersion, sensitivity of dispersion, coefficient of variation and hypothetical extraction method (HEM). In this paper, we apply the HEM due to its capability in considering the relative magnitude of each sector's final demand in the economy and the relative effect of a sector on overall output (Song et al., 2006). The central idea of the HEM is that the hypothetical elimination of a complete sector in the economic system allows us to estimate the economy-wide contribution of the 
sector (Temurshoev \& Oosterhaven, 2014). Leaving the technical production process in a variant, it is thus assumed that the inputs required for the production are no longer delivered by the sector within the inter-sectoral system, but has its origin outside the system. In practice, it was previously used by Duarte et al. (2002) and Song et al. (2006) to analyse the economic impact of sectoral water use and construction sector in the Spanish economy, respectively. For Malaysia, it was utilised by Utit el al. (2015) and Saari et al. (2017) to study the economic impact of the waste sector and identify the drivers of the Malaysian economy.

For backward linkages, HEM nullifies the $i$-th column of the input-output coefficient matrix (i.e. matrix $\mathbf{A}$ ), denoted by $\mathbf{A}^{-i}$, and nullifies the $i$-th element of the final demand vector, denoted by $\mathbf{f}^{-i}$. As a consequence of this nullifying process, the vector of total output after extracting sector $i$ is given by:

$$
\mathbf{x}_{l}^{-i}=\mathbf{L}^{-i} \mathbf{f}^{-i} \text { with } \mathbf{L}^{-i}=\left(\mathbf{I}-\mathbf{A}^{-i}\right)^{-1}
$$

For forward linkages, HEM nullifies the $i$-th row of the output coefficient matrix (i.e. matrix $\mathbf{B})$, denoted by $\mathbf{B}^{-i}$, and nullifies the $i$-th element of the primary input vector, denoted by $\mathbf{d}^{-i}$. Thus, the total input after extracting sector $i$ is given by:

$$
\mathbf{x}_{b}^{-i}=\left(\mathbf{d}^{-i}\right)^{\prime} \mathbf{G}^{-i} \text { with } \mathbf{G}^{-i}=\left(\mathbf{I}-\mathbf{B}^{-i}\right)^{-1}
$$

Coefficients in matrix B are also known as elements of the Ghosh inverse matrix. The Ghosh model is a supply-driven model, where the value-added and imports are the exogenous variables, and the final demand is the endogenous variable. It provides an alternative interpretation that relates to sectoral gross production to the primary inputs, that is, to a unit of value entering the inter-industry system at the beginning of the production process. Technically, the supply-driven model is operated by 'rotating' or transposing the vertical (column) view of the input-output model to a horizontal (row) view. In short, the Ghosh model can be summarised as follows:

$$
\mathbf{x}^{\prime}=\mathbf{i}^{\prime} \hat{\mathbf{x}} \mathbf{B}+\mathbf{d}^{\prime}=\mathbf{x}^{\prime} \mathbf{B}+\mathbf{d}^{\prime}
$$

where $\mathbf{i}^{\prime} \hat{\mathbf{x}}=\mathbf{x}^{\prime}, \mathbf{B}\left(\mathbf{B}=\hat{\mathbf{x}}^{-1} \mathbf{Z}\right)$ represents the output coefficient matrix and $\mathbf{d}^{\prime}$ is the vector of primary inputs (i.e. value-added and imports). Each element of the output coefficient matrix shows the delivery $z_{i j}$ of commodity sector $i$ to sector $j$ per unit of the seller's output. The solution for (9) is:

$$
\mathbf{X}^{\prime}=\mathbf{d}^{\prime}(\mathbf{I}-\mathbf{B})^{-1}=\mathbf{d}^{\prime} \mathbf{G}
$$

Based on equations (7) and (8), the normalised backward and forward linkages due to the complete extraction can be derived as follows:

$$
\dot{B}_{i}=\frac{\mathbf{i}^{\prime} \mathbf{x}-\mathbf{i}^{\prime} \mathbf{x}_{l}^{-i}}{x_{i}} \text { and } \dot{F}_{j}=\frac{\mathbf{x}^{\prime} \mathbf{i}-\left(\mathbf{x}_{b}^{-i}\right)^{\prime} \mathbf{i}}{x_{i}}
$$

where $\mathbf{i}^{\prime} \mathbf{x}-\mathbf{i}^{\prime} \mathbf{x}_{l}^{-i}$ and $\mathbf{x}^{\prime} \mathbf{i}-\left(\mathbf{x}_{b}^{-i}\right)^{\prime} \mathbf{i}$ represent the total output and total input after extraction of the sector $i$. 


\subsection{Footprints Measure}

To complement the findings for multiplier and linkages, this paper conducts the footprints analysis to inform the amount of recycled materials embodied in the economy. There are two types of outcomes derived from this analysis, the embodied recycled materials in the demand components (domestic and export demands) and the sectoral embodiment. For the embodiment in the demand components, it does not involve any model development as the information are available along the row of the recycling sector in the input-output tables. For the sectoral embodiment, the information is estimated based on the difference between the level of input in the economy before $\mathbf{x}$ and after the HEM, $\mathbf{x}_{b}^{-i}$.

$$
\Delta \mathbf{x}=\mathbf{x}-\mathbf{x}_{b}^{-i}
$$

\subsection{Data Source and Classification}

The main data set used in this paper are the input-output tables for base years 2005, 2010 and 2015 (DOSM, 2010, 2014, 2018). For the 2005 data set, the table consists of 120 sectors and is classified according to the 2000 Malaysia Standard Industrial Classification (MSIC). Meanwhile, the 2010 and 2015 input-output tables consist of 124 sectors and are classified according to the MSIC 2008. Based on the different type of classification used, the sectors listed in the 2000 input-output table are harmonised to the latest classification. The harmonisation is done by mapping the list of activities based on MSIC 2000 to MSIC 2008.

Table 2. List of economic activities according to MSIC 2008 under the Sewerage, Waste Collection and Remediation Activities sector

\section{MSIC 2008 Economic activities}

$37000 \quad$ Sewerage activities

38111 Collection of non-hazardous solid waste (i.e. garbage) within a local area

$38112 \quad$ Collection of recyclable materials

38113 Collection of refuse in litter-bins in public places

$38114 \quad$ Collection of construction and demolition waste

38115 Operation of waste transfer stations for non-hazardous waste

$38121 \quad$ Collection of hazardous waste

38122 Operation of waste transfer stations for hazardous waste

$38210 \quad$ Treatment and disposal of non-hazardous waste

$38220 \quad$ Treatment and disposal of hazardous waste

$38301 \quad$ Mechanical crushing of metal waste

38302 Dismantling of automobiles, computers, televisions and other equipment for material recover

38303 Reclaiming of rubber such as used tires to produce secondary raw material

$38304 \quad$ Reuse of rubber products

$38309 \quad$ Recycling of textile fibres

$39000 \quad$ Remediation activities and other waste management services

Source: DOSM (2008). 
The outcome from the harmonisation process shows that the recycling sector in the economy can be referred to as the Sewerage, Waste Collection and Remediation Activities which is a Services sub-sector. Table 2 describes the list of economic activities (classified according to MSIC 2008) that are available under the recycling sector.

Despite the fact that the recycling sector is formed through a group of economic activities which share a similar business nature (refer to Table 2), results from the input-output analysis are only available at the sectoral level. For further analysis at the activities level, the sector needs to be disaggregated and it is considered beyond our scope of study.

\section{Results and Discussion}

This paper assesses the economic impact of the recycling sector in Malaysia by using the input-output modelling technique. Specifically, models developed in section 3.2 and 3.3, including the models that involved the HEM operation are applied on inputoutput tables for base years 2005, 2010 and 2015. Results from the analyses are structured into three subsections. The first subsection starts the discussion by providing the overview of the recycling sector. The next subsection presents the results for the economic impact. Finally, the third subsection discusses the recycling sector's footprints in the economy.

\subsection{Overview of the Recycling Sector}

Recycling sector is an important aspect of any economy. The existence of a strong and sustainable recycling sector is essential for the economy to utilise resources efficiently and maximise the full value of materials. Based on the data between 2010-2015, the size of the recycling sector in Malaysia was recorded growing from $0.24 \%$ to $0.25 \%$ (DOSM, 2014, 2018)2. Despite the marginal growth, recycling rate continue to improve at an average annual rate of $12.3 \%$ between $2015-2019$, with the latest recycling rate recorded at $28.1 \%$ in 2019 (DOSM, 2020). Due to the drastic improvement, Malaysia was able to achieve the $22.0 \%$ recycling rate target underlined in the National Solid Waste Management Policy 2016. Table 3 presents the principal statistics for the recycling sector in Malaysia.

Based on Table 3, it is apparent that the recycling sector is mainly driven by private establishments. Between 2010-2015, individual proprietorship and private limited company are found to constitute more than $90 \%$ of the total recycling-based establishments. In 2015, the former has recorded a drastic decline in the share of establishments due to the strong growth in the number of private limited company. The study by Jereme et al. (2015) showed that this situation is primarily explained by the privatisation of waste management sector that started in 1994.

2 The size of the recycling sector is estimated based on the size of its final demand. The data used for the estimation are derived from the input-output tables for base year 2010 and 2015. It must be noted that we are unable to estimate the current size of the sector due to the fact that the input-output table is only published once in every five years. 
From Waste to Wealth: Identifying the Economic Impact of the Recycling Sector in Malaysia

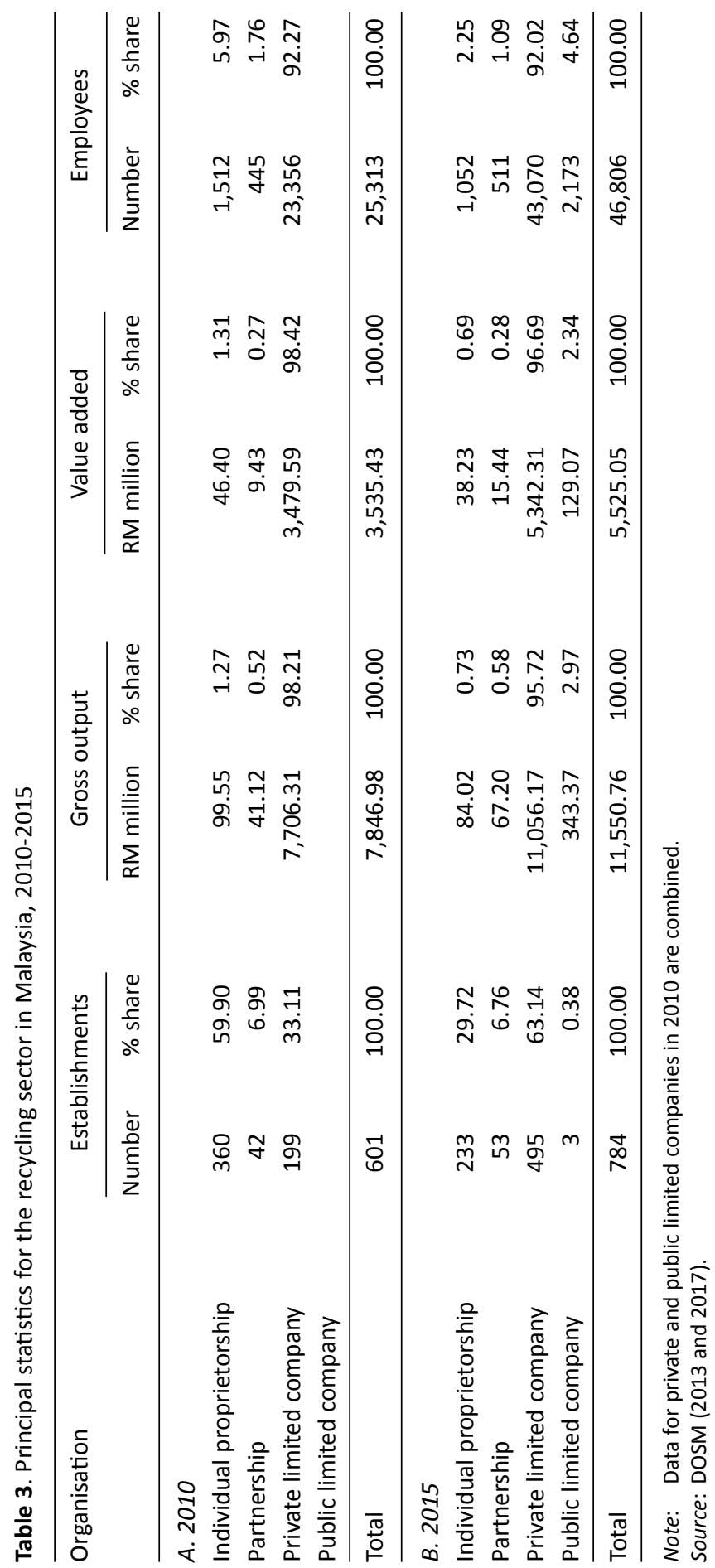


In relation to the economic contribution, the sector created RM11.55 billion of gross output, generated RM5.52 billion of value added and provided 46,806 of employment opportunities in 2015. The size of the contribution for each of the economic indicators increased respectively by $6.66 \%, 7.72 \%$ and $10.79 \%$ from 2010 . Linking these findings to the type of organisations, private limited company are found to dominate the level of contributions. To provide more insights on the economic impact of the recycling sector, the following section details the results from the multiplier and linkages analyses.

\subsection{Economic Impact of the Recycling Sector}

The economic impact of a production sector is commonly assessed using two types of analyses, the multiplier and linkages. The methodology for assessing these indicators are well described by equations (6) and (11) in section 3.2. Figure 1 presents the results of value-added multiplier and the linkages effects of the recycling sector in Malaysia.

Between 2005-2010, the multiplier indicated a reduction trend from 0.80 to 0.79 . The findings suggest that the amount of value-added created per Ringgit of output in the economy has reduced from RM0.80 in 2005 to RM0.79 in 2010. In 2015, the multiplier impact increased to RM0.88. Among the factors that explain the changes is the consumption of imported intermediate inputs. Imports of goods and services represent leakages to the domestic economy because they are not produced domestically, and thus creating no value-added (Hassan et al., 2018). Observation of the import trend shows that the consumption of imports increased by $118 \%$ between 2005 and 2010 and decreased by $-48 \%$ in 2015 .

For the interpretation of linkage indices, the backward and forward linkages may fall into four potential degrees of linkages. In 2005, the recycling sector was classified as a key sector in the economy due to its above-average backward and forward linkages. Specifically, the linkage indices are recorded at 1.10 for backward linkage and 1.39 for

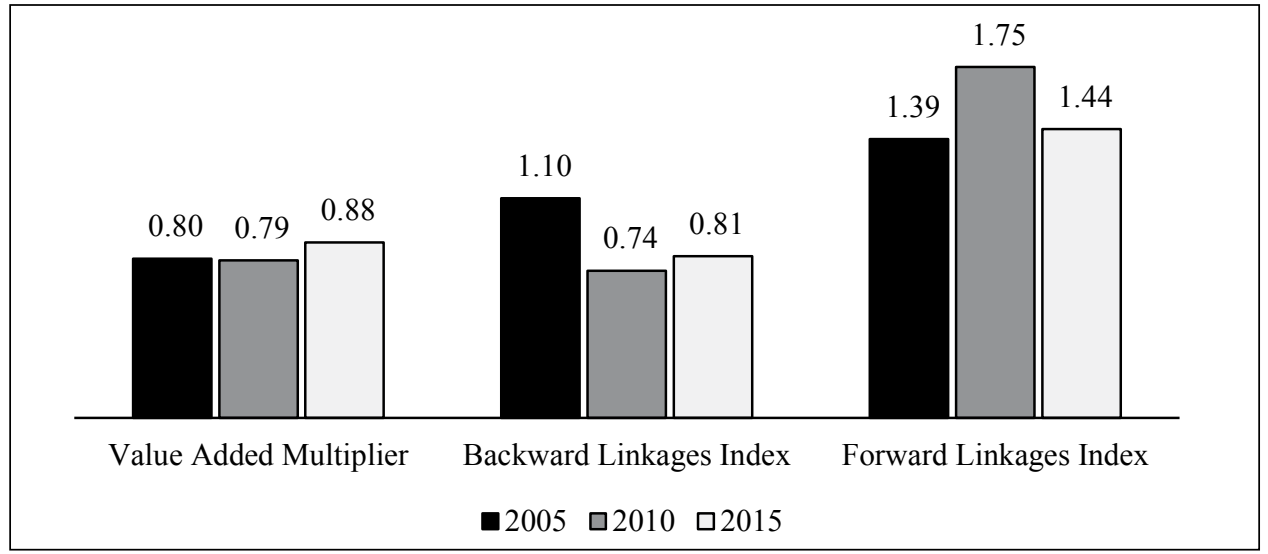

Figure 1. Value-added multiplier and linkage effects of the recycling sector, 2005-2015 Note: Value-added multiplier is interpreted in Ringgit, while linkages are interpreted by index. Source: Computed based on equations (6) and (11). 
forward linkage. Being a key sector, the recycling sector has a high integration level with other domestic sectors. It also reflects the important role of the recycling sector in pulling and supporting the growth of other sectors.

However, in 2010 and 2015, the recycling sector transformed into a strategic sector. Its backward linkage indices declined to less than the average economy, while its forward linkage indices remained high. As a strategic sector, its role is reduced to only supporting the growth of other domestic sectors. Most of the output from the recycling sector support production activities in other sectors. Meanwhile, growth in its final demand brings less spillover effects to other sectors because of the decreasing demand for domestic intermediate inputs.

Nevertheless, the decreasing demand is not due to the role of imports, but due to the increase in capital investment. The findings reflect that the recycling sector has experienced a significant change in its production technology, which leads to lower dependency on intermediate inputs and increases production capacity. Similarly, Di Vita (2001) also showed that the recycling sector would eventually experience a technological change in its production activity, thus increasing the quantity of secondary materials produced.

Overall, the analyses prove that the recycling sector does bring a significant contribution to the economy. Its value-added multiplier impact is not only large, but also associated with a significant degree of spillover effects. In comparison to other large sectors in the Malaysian economy such as Oil Palm, and Coke and Refined Petroleum Products, these sectors produce RM0.89 and RM0.79 of value-added multipliers, respectively. With regards to linkages, Oil Palm is also labelled as a strategic sector and Coke and Refined Petroleum Products as an independent sector. Thus, the findings provide clear empirical evidence for the economic importance of the recycling sector, with relatively better performance than the Coke and Refined Petroleum Products sector.

\subsection{Footprints of the Recycling Sector}

This subsection assesses the footprints of the recycling sector between 2005-2015 by observing the amount of recycled materials embodied in the demand components (domestic and export demands) and production sectors. To obtain the level of recycled materials embodiment in the demand components, the information are extracted along the row of the recycling sector in the input-output tables. Meanwhile, the sectoral embodiment is estimated based on equation (12) in section 3.3.

Based on Table 4, 53.9\% of the recycled materials in 2005 were embodied in private consumption, implying that the households utilised most of the output from the recycling sector. However, it must be noted that the large share of embodiment does not reflect the direct use by households. Commonly, the materials flowed into this demand component through the consumption of household commodities such as canned food and plastic products that require the use of recycled materials in their production. The detailed list of products consumed and the level of embodied recycled materials are not provided in this paper as this exercise is considered beyond the scope of this study. Another important demand component was the intermediate demand, 
which embodied $46.0 \%$ of the total recycled materials. Table 5 details the information for the share of recycled materials embodied at the sectoral level. The top three sectors with the largest share of recycled materials embodied in 2005 were Electricity and Gas (26.6\%), Wholesale and Retail Trade (6.3\%) and Electrical and Electronic (4.4\%).

Table 4. Embodied recycled materials in demand components, 2005-2015

\begin{tabular}{|c|c|c|c|c|c|c|}
\hline \multirow[t]{2}{*}{ Component } & \multicolumn{2}{|c|}{2005} & \multicolumn{2}{|c|}{2010} & \multicolumn{2}{|c|}{2015} \\
\hline & RM million & $\%$ share & RM million & $\%$ share & RM million & $\%$ share \\
\hline Intermediate demand & $2,854.50$ & 46.00 & $7,675.56$ & 69.12 & $8,882.85$ & 69.79 \\
\hline Private consumption & $3,346.92$ & 53.94 & $3,062.13$ & 27.57 & $3,613.13$ & 28.39 \\
\hline Government consumption & - & - & - & - & 232.40 & 1.83 \\
\hline Investment & - & - & 271.55 & 2.45 & -2.26 & -0.02 \\
\hline Exports & 3.74 & 0.06 & 96.17 & 0.87 & 1.85 & 0.01 \\
\hline Total demand & $6,205.16$ & 100.00 & $11,105.41$ & 100.00 & $12,727.97$ & 100.00 \\
\hline
\end{tabular}

Note: Domestic demand components consist of intermediate demand, private consumption, government consumption and investment (including gross fixed capital formation and change in inventory).

Source: Derived from the input-output tables.

Table 5. Embodied recycled materials in production sectors, 2005-2015

\begin{tabular}{|c|c|c|c|c|c|c|}
\hline \multirow[t]{2}{*}{ Sector } & \multicolumn{2}{|c|}{2005} & \multicolumn{2}{|c|}{2010} & \multicolumn{2}{|c|}{2015} \\
\hline & RM million & $\%$ share & RM million & $\%$ share & RM million & $\%$ share \\
\hline Agriculture & 34.78 & 1.65 & 598.89 & 7.56 & 158.40 & 1.72 \\
\hline Mining and Quarrying & 17.44 & 0.83 & 42.41 & 0.54 & 118.39 & 1.28 \\
\hline Food and Beverages & 65.50 & 3.12 & 696.47 & 8.80 & 741.31 & 8.04 \\
\hline Animal Feeds & 2.20 & 0.10 & 146.58 & 1.85 & 19.92 & 0.22 \\
\hline Tobacco Products & 2.19 & 0.10 & 1.49 & 0.02 & 2.70 & 0.03 \\
\hline Textiles and Wearing Apparels & 16.73 & 0.80 & 61.66 & 0.78 & 62.16 & 0.67 \\
\hline Wood and Wood Products & 30.96 & 1.47 & 130.05 & 1.64 & 138.09 & 1.50 \\
\hline Publishing and Printing & 5.01 & 0.24 & 11.38 & 0.14 & 26.02 & 0.28 \\
\hline Petroleum Refinery & 33.63 & 1.60 & 48.77 & 0.62 & 140.62 & 1.53 \\
\hline Chemical Products & 53.21 & 2.53 & 592.43 & 7.48 & 289.51 & 3.14 \\
\hline Rubber and Plastic Products & 38.88 & 1.85 & 992.50 & 12.54 & 214.58 & 2.33 \\
\hline Glass and Mineral Products & 19.01 & 0.90 & 347.19 & 4.39 & 138.98 & 1.51 \\
\hline Metal Products & 67.16 & 3.19 & 429.79 & 5.43 & 295.33 & 3.20 \\
\hline Machineries & 41.11 & 1.96 & 106.55 & 1.35 & 158.03 & 1.71 \\
\hline Electrical and Electronic & 92.32 & 4.39 & 237.56 & 3.00 & 416.04 & 4.51 \\
\hline Other Manufacturing & 58.31 & 2.77 & 186.17 & 2.35 & 267.73 & 2.90 \\
\hline Electricity and Gas & 558.60 & 26.57 & 155.75 & 1.97 & 134.63 & 1.46 \\
\hline Construction & 49.54 & 2.36 & 323.75 & 4.09 & 384.93 & 4.18 \\
\hline Wholesale and Retail Trade & 132.24 & 6.29 & 984.91 & 12.44 & $1,563.13$ & 16.96 \\
\hline Other Services & 783.16 & 37.26 & $1,823.31$ & 23.03 & $3,945.83$ & 42.81 \\
\hline Total Economy & $2,102.00$ & 100.00 & $7,917.62$ & 100.00 & $9,216.33$ & 100.00 \\
\hline
\end{tabular}

Source: Computed based on equation (12). 
As opposed to 2005 , about $70 \%$ of recycled materials were embodied in the intermediate demand in 2010 and 2015. Specifically, the shares were $69.1 \%$ in 2010 and $69.8 \%$ in 2015 . These findings are reflective of its role as a strategic sector in the economy (refer to subsection 4.2). In 2010, the top three sectors with the largest share of recycled materials were Rubber and Plastic Products (12.5\%), Wholesale and Retail Trade (12.4\%) and Food and Beverages (8.8\%). The top three sectors in 2015 were Wholesale and Retail Trade (17.0\%), Food and Beverages (8.0\%) and Electrical and Electronic (4.5\%). From 2005-2015, Wholesale and Retail Trade was found to be the common sector with the largest share of recycled materials embodied. The findings are supported by the role of the sector as an intermediary between business-to-business and business-to-consumer (Peterson \& Balasubramanian, 2002).

Besides the top three sectors, recycled waste materials are also equally important for other production sectors. In the Construction sector, particularly for the Civil Engineering subsector, recycled asphalt pavement and recycled asphalt shingles are used for the construction of bituminous roadways (Yang et al., 2015). In the Glass and Mineral Products sector, which partly represents the concrete production activity, without recycled materials, the production of concrete would require $50 \%$ of raw materials, $40 \%$ of energy and generates $50 \%$ of waste (Behera et al., 2014). In the Electrical and Electronic sector, the exponential growth of waste that enters the landfill is a valuable secondary resource that presents cost-saving opportunities, because recoverable assets would otherwise be worthless and hazardous to environmental and human health (Khor \& Udin, 2012). Overall, the use of recycled materials contributes to the cost and energy-saving, and reduce consumption of raw materials.

Despite the positive observations, there is a clear trend that most of the sectors only recorded the improvement in the embodiment shares between 2005-2010, while reduction are recorded between 2010-2015. For example, the Agriculture sector recorded an increase of $5.91 \%$ between $2005-2010$ and a decrease of $5.84 \%$ between 2010-2015. Relating these findings to the backward linkages (refer to Figure 1), a similar trend is observable. Coupled with the fact that the developed input-output models are directly applied on the production system (through the application on input-output tables), it informs that the trend is largely influenced by the changes in the production structure.

\section{Conclusions}

This paper assesses the economic impact of the recycling sector in Malaysia by providing empirical evidence for its potential in the whole economic ecosystem. The assessment of the impact was performed by analysing the input-output multiplier and linkages, modelled using the national input-output tables for 2005, 2010 and 2015 base years. Results indicate that the recycling sector has a high potential in generating valueadded multipliers and is associated with high spillover effects. It also performs relatively better than the Coke and Refined Petroleum Products sector, which is one of the largest sectors in the Malaysian economy. As a strategic sector, about $70 \%$ of its products are embodied in the intermediate demand in recent years. It means that the waste from the recycling sector has been transformed into different products that are eventually 
used for reproduction by other sectors. The reproduction along the supply-chain relatively conforms to circular economic practices.

The footprint level of the recycling sector is also shown to be substantial, implying its importance in supporting the growth of other production sectors. At the sectoral level, most of the recycled materials are utilised by the Wholesale and Retail Trade sector with an increasing utilisation level recorded over the years. Among the factors that explain this finding is the role of the Wholesale and Retail Trade as an intermediary sector between business-to-business and business-to-consumer. For other sectors, the reduction in the level of embodiment, particularly between 2010-2015 is mainly explained by the changes in their production structure.

With regard to policy implications, we suggest two important strategic recommendations. First, the recycling sector should be prioritised in the short-term and long-term development plans. This sector is considered as a strategic sector because it has great potential in generating value-added multiplier and supporting the growth of other sectors. Stimulating investments in the recycling sector, such as investment in green recycling technology, would positively affect all other sectors that are closely connected to the sector. Second, the backward linkages between the recycling sector and other production sectors should be improved and strengthened. The production activities of all economic sectors dispose wastes in the form of recyclable and nonrecyclable materials. Indeed, the non-recyclable materials end up in landfills and cause environmental degradation. However, the recyclable materials from the production activities have the opportunities to be separated and channelled to the recycling sector for recycling activities, which eventually can transform waste into wealth.

This paper has two main limitations. First, we are unable to separate the recycling sector according to detailed recycling activities. We only use the data for aggregated sector as available in the input-output tables. Aggregated data limit the assessment of the economic impact for the whole sector as detailed information on the recycling activities level can be more useful for targeted policy planning. Second, the impact of the recycling sector is assessed based on multiplier, linkages and footprints, that do not include other measures, such as efficiency, productivity and environmental impact. The assessment of efficiency and productivity are also important because they provide some indications on the level of competitiveness of the sector in the Malaysian economy, representing the economics of scale of the sector. Additionally, our work also excludes the environmental impact of promoting the recycling sector. It is indisputable that promoting investment in the recycling sector may induce higher carbon footprints, which is unfavourable to the Sustainable Development Goals (SDGs). To conclude, we lay these caveats as limitations of our work that offer opportunities for future research.

\section{References}

Afroz, R., \& Masud, M.M. (2011). Using a contingent valuation approach for improved solid waste management facility: Evidence from Kuala Lumpur, Malaysia. Waste Management, 31(4), 800-808. https://doi.org/10.1016/j.wasman.2010.10.028

Baggs, J. (2009). International trade in hazardous waste. Review of International Economics, 17(1), 1-16. https://doi.org/10.1111/j.1467-9396.2008.00778.x 
Begum, R.A., Siwar, C., Pereira, J.J., \& Jaafar, A.H. (2009). Attitude and behavioral factors in waste management in the construction industry of Malaysia. Resources, Conservation and Recycling, 53(6), 321-328. https://doi.org/10.1016/j.resconrec.2009.01.005

Behera, M., Bhattacharyya, S.K., Minocha, A.K., Deoliya, R., \& Maiti, S. (2014). Recycled aggregate from C\&D waste $\&$ its use in concrete - a breakthrough towards sustainability in construction sector: A review. Construction and Building Materials, 68, 501-516. https://doi. org/10.1016/j.conbuildmat.2014.07.003

Department of Statistics Malaysia. (2008). Malaysia Standard Industrial Classification 2008.

Department of Statistics Malaysia. (2010). Input-output tables Malaysia 2005.

Department of Statistics Malaysia. (2013). Economic Census 2011 - Water Supply; Sewerage, Waste Management and Remediation Activities.

Department of Statistics Malaysia. (2014). Input-output tables Malaysia 2010.

Department of Statistics Malaysia. (2017). Economic Census 2016 - Water Supply; Sewerage, Waste Management and Remediation Activities.

Department of Statistics Malaysia. (2018). Input-output tables Malaysia 2015.

Department of Statistics Malaysia. (2020). Compendium of Environment Statistics 2020.

Di Vita, G. (2001). Technological change, growth and waste recycling. Energy Economics, 23(5), 549-567. https://doi.org/10.1016/S0140-9883(01)00075-5

Duarte, R., Sanchez-Choliz, J., \& Bielsa, J. (2002). Water use in the Spanish economy: An inputoutput approach. Ecological Economics, 43(1), 71-85. https://doi.org/10.1016/S0921-8009 (02)00183-0

Elliott, L. (2007). Transnational environmental crime in the Asia Pacific: An 'un(der)securitized' security problem? The Pacific Review, 20(4), 499-522. https://doi.org/10.1080/0951 2740701671995

Gerbens-Leenes, P.W., Nonhebel, S., \& Krol, M.S. (2010). Food consumption patterns and economic growth. Increasing affluence and the use of natural resources. Appetite, 55(3), 597-608. https://doi.org/10.1016/j.appet.2010.09.013

Hassan, M.N., Rahman, R.A., Chong, T.L., Zakaria, Z., \& Awang, M. (2000). Waste recycling in Malaysia: Problems and prospects. Waste Management and Research, 18(4), 320-328. https://doi.org/10.1177\%2F0734242X0001800404

Hassan, A., Saari, M.Y., Hamid, N.A., Utit, C., \& Maji, I.K. (2018). A heuristic approach to measure contribution of foreign trade to growth. Malaysian Journal of Economic Studies, 55(1), 115131. https://doi.org/10.22452/MJES.vol55no1.7

Hong, M-C, \& Narayanan, S. (2006). Restoring the shine to a pearl: Recycling behaviour in Penang, Malaysia. Development and Change, 37(5), 1117-1136. https://doi.org/10.1111/j.14677660.2006.00515.x

Hotta, Y., Elder, M., Mori, H., \& Tanaka, M. (2008). Policy considerations for establishing an environmentally sound regional material flow in East Asia. The Journal of Environment \& Development, 17(1), 26-50. https://doi.org/10.1177\%2F1070496507312562

Japan International Cooperation Agency (JICA). (2006). The Study on National Waste Minimisation in Malaysia. https://jpspn.kpkt.gov.my/resources/index/user_1/Sumber_Rujukan/kajian/PSP/ Supporting_Report_1/SupportingReport1_V1.pdf

Jereme, I.A., Alam, M.M., \& Siwar, C. (2015). Waste recycling in Malaysia: Transition from developing to developed country. Indian Journal of Education and Information Management, 4(1), 1-14.

Johari, A., Alkali, H., Hashim, H., Ahmed, S.I., \& Mat, R. (2014). Municipal solid waste management and potential revenue from recycling in Malaysia. Modern Applied Science, 8(4), 37. https://doi.org/10.5539/mas.v8n4p37

Khor, K.S., \& Udin, Z.M. (2012). Impact of reverse logistics product disposition towards business performance in Malaysian E\&E companies. Journal of Supply Chain and Customer Relationship Management, 2012, 1-19. 
Lipman, Z. (2002). A dirty dilemma: The hazardous waste trade. Harvard International Review, 23(4), 67-71.

Manaf, L.A., Samah, M.A.A., \& Zukki, N.I.M. (2009). Municipal solid waste management in Malaysia: Practices and challenges. Waste Management, 29(11), 2902-2906. https://doi. org/10.1016/j.wasman.2008.07.015

Miller, R.E., \& Blair, P.D. (2009). Input-output analysis: Foundations and extensions. Cambridge University Press.

Moh, Y.C., \& Manaf, L.A. (2014). Overview of household solid waste recycling policy status and challenges in Malaysia. Resources, Conservation and Recycling, 82, 50-61. https://doi. org/10.1016/j.resconrec.2013.11.004

Moh, Y.C., \& Manaf, L.A. (2017). Solid waste management transformation and future challenges of source separation and recycling practice in Malaysia. Resources, Conservation and Recycling, 116, 1-14. https://doi.org/10.1016/j.resconrec.2016.09.012

Mohamad, Z.F., Idris, N., Baharuddin, A., Muhammad, A., \& Sulaiman, N.M.N. (2012). The role of religious community in recycling: Empirical insights from Malaysia. Resources, Conservation and Recycling, 58, 143-151. https://doi.org/10.1016/j.resconrec.2011.09.020

Murad, W., \& Siwar, C. (2007). Waste management and recycling practices of the urban poor: A case study in Kuala Lumpur city, Malaysia. Waste Management \& Research, 25(1), 3-13. https://doi.org/10.1177\%2F0734242X07070766

Omran, A., Mahmood, A., Abdul Aziz, H., \& Robinson, G.M. (2009). Investigating households attitude toward recycling of solid waste in Malaysia: A case study. International Journal of Environmental Research, 3(2), 275-288.

Periathamby, A., Hamid, F.S., \& Khidzir, K. (2009). Evolution of solid waste management in Malaysia: Impacts and implications of the solid waste bill, 2007. Journal of Material Cycles and Waste Management, 11(2), 96-103. https://doi.org/10.1007/s10163-008-0231-3

Peterson, R.A., \& Balasubramanian, S. (2002). Retailing in the 21st century: Reflections and prologue to research. Journal of Retailing, 78(1), 9-16. https://doi.org/10.1016/S0022-4359 (01)00062-8

Ramayah, T., Lee, J.W.C., \& Lim, S. (2012). Sustaining the environment through recycling: An empirical study. Journal of Environmental Management, 102, 141-147. https://doi.org/ 10.1016/j.jenvman.2012.02.025

Ray, A. (2008). Waste management in developing Asia: Can trade and cooperation help? The Journal of Environment \& Development, 17(1), 3-25. https://doi.org/10.1177\%2F1070 496507310742

Saari, M.Y., Utit, C., Hamid, N.A., Maji, I.K., \& Hassan, A. (2017). Identifying drivers of the Malaysian economy using policy-relevant measures. Malaysian Journal of Economic Studies, 54(1), 23-40. https://doi.org/10.22452/MJES.vol54no1.2

Saari, M.Y., Habibullah, M.S., Utit, C., \& Maji, I.K. (2018). Economic impacts of petroleum industry in states of Pahang and Terengganu. Jurnal Ekonomi Malaysia, 52(2), 149-161.

Singh, J., Laurenti, R., Sinha, R., \& Frostell, B. (2014). Progress and challenges to the global waste management system. Waste Management \& Research, 32(9), 800-812. https://doi.org/10. $1177 \% 2 F 0734242 X 14537868$

Song, Y., Liu, C., \& Langston, C. (2006). Linkage measures of the construction sector using the hypothetical extraction method. Construction Management and Economics, 24(6), 579-589. https://doi.org/10.1080/01446190500435358

Strohm, L.A. (1993). The environmental politics of the international waste trade. The Journal of Environment \& Development, 2(2), 129-153. https://doi.org/10.1177\%2F1070496593 00200209

Subhan, M., Abdul Ghani, A.B., \& Joarder, M.H.R. (2014). Urban community willingness to pay for improved solid waste management in a Malaysian municipality: A choice modeling approach. Asian Social Science, 10(18), 122-136. https://doi.org/ 10.20961/jiep.v9i1.2096 
Temurshoev, U., \& Oosterhaven, J. (2014). Analytical and empirical comparison of policy-relevant key sector measures. Spatial Economic Analysis, 9(3), 284-308. https://doi.org/10.1080/1742 1772.2014.930168

United Nations Environment Programme. (2015). Global waste management outlook. https:// www.uncclearn.org/wp-content/uploads/library/unep23092015.pdf

Utit, C., Saari, M.Y., Hassan, A., \& Ismail, T.H.T. (2015). Measuring the embodied waste among industries in Malaysia. Procedia Environmental Sciences, 30, 228-231. https://doi.org/ 10.1016/j.proenv.2015.10.041

Wang, W., Themelis, N.J., Sun, K., Bourtsalas, A.C., Huang, Q., Zhang, Y., \& Wu, Z. (2019). Current influence of China's ban on plastic waste imports. Waste Disposal \& Sustainable Energy, 1(1), 67-78. https://doi.org/10.1007/s42768-019-00005-z

Wu, Wenheng, \& Niu, Shuwen. (2008). Impact study on human activity to the resourceenvironment based on the consumption level difference of China's provinces or autonomous regions. China Population, Resources and Environment, 18(4), 121-127. https://doi.org/ 10.1016/S1872-583X(09)60015-2

World Bank. (2018). Trends in solid waste management. http://datatopics.worldbank.org/what-awaste/trends_in_solid_waste_management.html

Wynne, B. (1989). The toxic waste trade: International regulatory issues and options. Third World Quarterly, 11(3), 120-146. https://doi.org/10.1080/01436598908420177

Yang, R., Kang, S., Ozer, H., \& Al-Qadi, I.L. (2015). Environmental and economic analyses of recycled asphalt concrete mixtures based on material production and potential performance. Resources, Conservation and Recycling, 104(A), 141-151. https://doi.org/10.1016/j.resconrec. 2015.08.014

Zen, I.S., Noor, Z.Z., \& Yusuf, R.O. (2014). The profiles of household solid waste recyclers and non-recyclers in Kuala Lumpur, Malaysia. Habitat International, 42, 83-89. https://doi. org/10.1016/j.habitatint.2013.10.010

Zen, I.S., \& Siwar, C. (2015). An analysis of household acceptance of curbside recycling scheme in Kuala Lumpur, Malaysia. Habitat International, 47, 248-255. https://doi.org/10.1016/j. habitatint.2015.01.014 
